\title{
A practical guide to granulocyte transfusion therapy
}

\author{
J. A. RUSSELl AND R. L. POWLES \\ From The Royal Marsden Hospital, Downs Road, Belmont, Sutton, Surrey
}

A major development for the supportive care of patients with bone marrow suppression has been the recent introduction of techniques for collecting granulocytes from suitable donors. There is increasing awareness in this country that granulocyte transfusion for infected neutropenic patients is now a practical possibility, and the demand for granulocytes from those centres able to provide this service has increased considerably. For example, the number of transfusions provided by the Royal Marsden Hospital in the year 1972/73 was 19; the figures for the following two years were 115 and 116. Equipment is now available which is cheaper and simpler to operate than the earlier machines, and this means that granulocyte transfusions can now be provided by centres unable to afford the expertise and equipment previously required. It seems therefore an appropriate time to give some account of the available methods of collecting granulocytes, the evidence for their value, and the indications for their use.

\section{The Need for Granulocyte Transfusions}

Since the introduction of routine platelet transfusions, infection has become the major cause of death in patients with bone marrow suppression (Levine et al, 1972). While germ-free environments and oral non-absorbable antibiotic regimes have done much to reduce the acquisition of infection in hospital (Jameson et al, 1971; Levine et al, 1973; Yates and Holland, 1973; Schimpff et al, 1975), infections still occur despite these measures, and many neutropenic patients are already infected when admitted to hospital. The effectiveness of many of the most useful antibiotics is reduced in the presence of neutropenia (Levine et al, 1972), and antibiotic resistance may well become more of a problem than it is at present (Greene et al, 1973). Attempting to reverse the fundamental defect of neutropenia by transfusion of granulocytes is a logical approach to this problem but it is complicated by the fact that only a small proportion of the total granulocyte pool of a normal individual is present in the circulation, and the mature granulocyte is a relatively shortlived cell. Thus a normal adult has approximately 1.5 to $3 \times 10^{10}$ circulating granulocytes which represents only $1-2 \%$ of the total granulocyte pool. The estimated daily turnover is about $1.2 \times 10^{11}$ cells, and the mature neutrophil spends on average only 10 hours in the circulation (Athens et al, 1961; Boggs, 1974). Using these figures, it can be seen that it would require the transfusion of the granulocytes from $\mathbf{4 0}$ to 80 units of donor blood simply to replace the normal daily requirement without compensating for the increased consumption of granulocytes due to infection. While it may not be necessary to give quite such large numbers of cells to obtain a therapeutic effect, some method of concentrating granulocytes from normal blood is clearly essential before the transfusion of useful numbers of these cells can be contemplated. An alternative is to use cells from patients with chronic granulocytic leukaemia (CGL) where there is often no need for concentration because of the high peripheral blood count.

\section{Collection of Granulocyte Concentrates}

The methods of collecting granulocyte concentrates depend on the circulation of donor blood through a device which selectively removes the granulocytes and returns processed blood into the opposite arm of the donor. The selective removal of granulocytes is performed by either a specially designed centrifuge bowl or a nylon fibre filter.

\section{CENTRIFUGAL CELL SEPARATORS}

In these machines anticoagulated donor blood passes into a centrifuge bowl where separation takes place into red cells and plasma between which is a layer of leucocytes. This layer can be removed into a bag and recombined red cells and plasma are returned to the donor. Two kinds of machine are available, depending on whether the filling of the bowl and the return of processed blood to the donor is continuous or discontinuous.

In the continuous-flow machines (IBM ${ }^{1}$ and 
Aminco $^{1}$ ), processed blood is removed from the bowl and returned to the donor continuously so the only change in blood volume is due to the slow continuous loss of buffy coat which should not normally exceed $500 \mathrm{ml}$. In these machines the centrifuge bowl is made of polycarbonate or stainless steel and requires sterilization, but all plastic tubing is disposable ${ }^{2}$.

The second kind of machine (Haemonetics Model $30^{3}$ ) operates on a discontinuous separation principle so that filling of the bowl and return of blood to the donor are separate processes. After granulocytes and platelets have been collected red cells and plasma removed from the bowl have to be returned to a transfusion bag whence they are reinfused into the donor under gravity while the subsequent filling of the bowl takes place. This means that the volume of blood outside the donor at any one time tends to be greater than with continuous-flow machines and the changes in blood volume are intermittent. Because both bowl and tubing for this machine are disposable it is relatively simple to operate. It is necessary to use acid-citrate-dextrose $\left(\mathrm{ACD}^{4}\right)$ as anticoagulant with this machine whereas heparin, which causes fewer side effects, can be used with the continuous-flow separators.

Other comparative merits of these machines are discussed in more detail below and illustrated in the table.

\section{FILTRATION LEUKAPHERESIS}

This technique, first described by Djerassi et al (1970), depends on the ability of granulocytes to adhere to nylon fibres from which they can subsequently be eluted. The procedure will be described in a little more detail because its simplicity means that it may possibly become much more widely used than the cell centrifuges.

The simplest form of apparatus required is illustrated (fig 1). Here the only mechanical device is a simple rotary pump. The filters consist of plastic cylinders filled with nylon fibres ${ }^{5}$. These filters and the connecting plastic tubing are primed with heparinized saline and all air bubbles are excluded from the system. After cannulation of both arms and connection of the cannulae to the circuit the donor is given a loading dose of 3000 units of heparin intravenously. While perfusion takes place hepari${ }^{1}$ V. A. Howe and Co Ltd, 88 Peterborough Road, London SW6.

'Avon Medicals Ltd, Capon Heaton, Birmingham B30 3DR. sHaemonetics Corporation, 368 Northolt Road, South Harrow, Middlesex HA2 8ES.

A concentrated solution containing sodium citrate $29.33 \%$ $\mathrm{w} / \mathrm{v}$ and citric acid $10.64 \% \mathrm{w} / \mathrm{v}$ can be made up by a hospital pharmacy. $30 \mathrm{ml}$ of this solution is then added to $400 \mathrm{ml}$ of sedimenting agent (see below).

'Leukopak (Fenwal Ltd), Travenol Laboratories, Thetford, Norfolk IP24 3SE. nized saline is added at a rate of $\mathbf{5 0 0 0}$ units per hour into the blood flowing out of one antecubital vein. This blood then passes through a device for monitoring the flow which can be an electronic pressure sensor $^{6}$ or a simple plastic chamber which collapses when flow from the vein is inadequate. The rotary pumps should preferably be placed before the filters because they occasionally collapse if blood is drawn through them, leading to poor granulocyte recovery. If more than one filter is being perfused, as is generally the case, separate or dual-channelled pumps must be used so that the volume flowing through each filter is known. The return of filtered blood to the donor must involve some mechanism to prevent air being pumped back. This can be achieved either by pumping blood into a re-infusion bag whence it is returned by gravity (fig 1 ) or by passing it through a bubble trap which activates a warning device and switches off the pumps automatically if air bubbles are present ${ }^{6}$. As bleeding and re-infusion are a continuous process, the total volume outside the donor need not exceed $300 \mathrm{ml}$ at any time. Because of variability in the number of granulocytes needed to saturate a single filter and variation of donor blood counts before and during leukapheresis, it is impossible to know exactly how much blood to perfuse on a single occasion. However, satisfactory yields are usually obtained by passing about 3 litres of blood through each filter. If two filters are used this usually gives a running time of 2 to 3 hours which is well tolerated by most donors. At the end of the procedure the small volume of red cells and plasma remaining in the circuit is flushed back to the donor with saline and the granulocytes are eluted from the nylon fibres by passing a litre of ACD/plasma/saline $\mathrm{pH} 6.5$ through each filter. The granulocyte suspension is then concentrated by centrifugation at $1000 \mathrm{~g}$ for 15 minutes and infused directly into the recipient.

\section{Collection of Granulocytes from Normal Donors}

\section{CELL YIELDS}

The number of granulocytes collected on a single occasion (hereafter referred to as granulocyte yield) depends on the total volume of blood processed and the granulocyte count of the donor during collection. The available collection procedures vary in their efficiency, ie, in the proportion of the estimated total number of cells processed which can be retrieved.

The buffy coat collected by a centrifuge from a normal donor tends to have a lower proportion of

${ }^{6}$ Such a device is fitted to continuous-flow separators and to the Fenwal leukapheresis pump. 


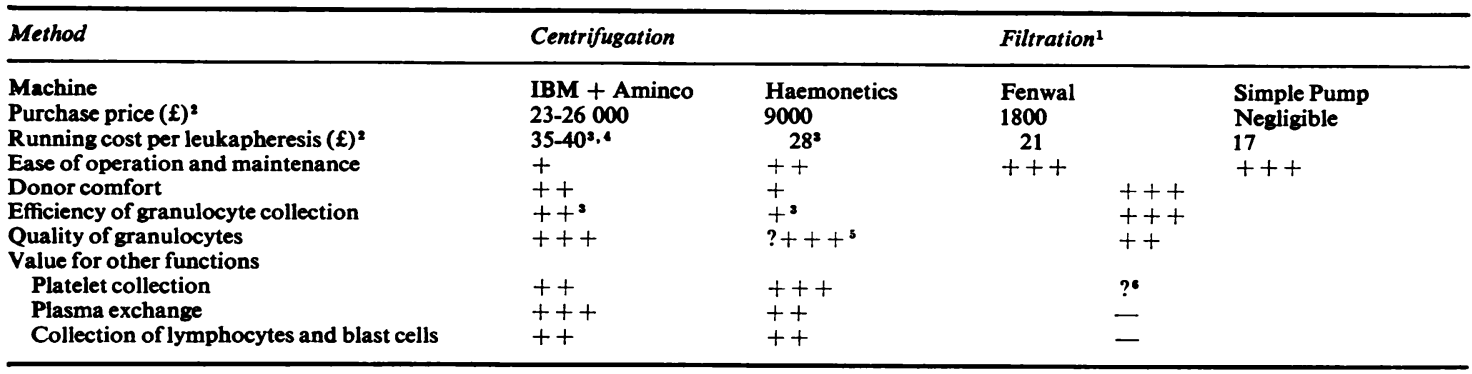

Table Relative merits of the available methods of granulocyte collection

1 May also be carried out with the centrifugal machines at a cost of about $£ 20$ per run. 'Prices can be only approximate because of infiation and fluctuating exchange rates.

Assumes the use of HES.

'Includes an estimate based on the finite life of a centrifuge bowl.

'There is no direct evidence concerning the quality of these cells but there is no reason to suspect that they will function differently from those collected by the continuous-flow machine unless the higher bowl speed has a damaging effect.

-The equivalent of several units of platelets may be collected by a single procedure but there is no direct evidence concerning the clinical effectiveness of these.

This table should be used as a rough guide only. Comparisons are made on a scale of + to +++ in order of increasing value. Some of the comparisons are necessarily subjective and are based on our own experience with these techniques.

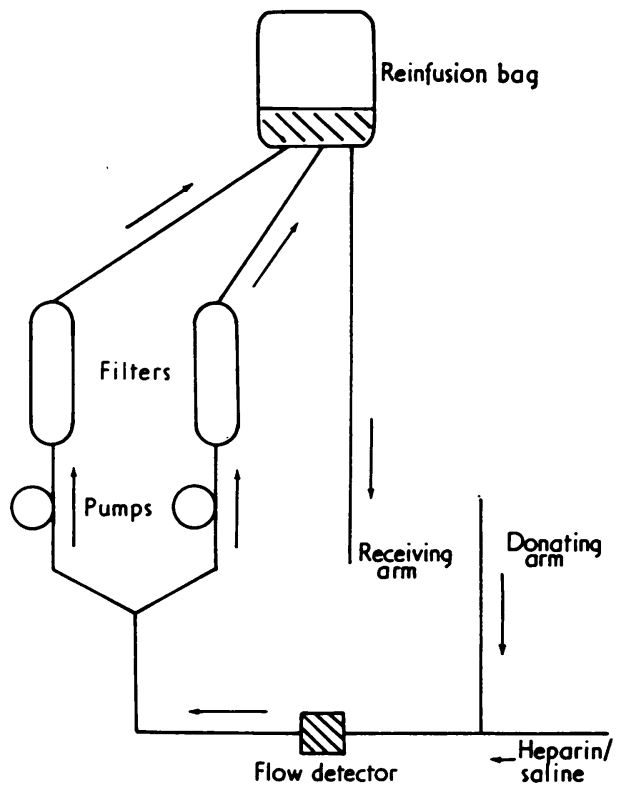

Fig 1 Diagram of simple apparatus for filtration leukapheresis.

granulocytes than the peripheral blood because the relatively high density of the granulocyte tends to make it sediment into the red cell layer. This means that a centrifuge is not as efficient for collecting granulocytes as it is for mononuclear cells. The efficiency of separation may be increased by adding a red cell sedimenting agent such as hydroxyethyl starch (HES) ${ }^{1}$ to the donor blood. This has the effect of decreasing the trapping of granulocytes in the red cell layer. Mishler et al (1974) have reported an increase in mean granulocyte yield from $1.0 \times 10^{10}$ to $4.7 \times 10^{10}$ with the use of HES. Another way of increasing the number of cells collected is to use prednisolone or dexamethasone to increase the circulating granulocyte count in the donor. Using both sedimenting agents and steroids, Benbunan $e t$ al (1975) have achieved a mean yield of $5.2 \times 10^{10}$, although the yields obtained by two other groups of workers using similar methods are somewhat lower at $1.7 \times 10^{10}$ (McCredie et al, 1975; Lowenthal et al, 1975).

The Haemonetics separator is not as efficient as the continuous-flow machines for collecting granulocytes. Sedimenting agents appear to be essential if useful numbers are to be obtained and it is logical to use steroids as well. Sussman and Colli (1975) have reported an average yield of $1.5 \times 10^{10}$ using both agents, and Huestis et al (1975) obtained a mean yield of $1.3 \times 10^{10}$ using a sedimenting agent without steroids.

Filtration is a more efficient way of collecting granulocytes than centrifugation. Once again steroids may be useful, and we were able to increase our mean yields from 2.0 to $3.2 \times 10^{10}$ by premedicating donors with dexamethasone. Most other workers appear to

${ }^{1} \mathrm{HES}$ is supplied by McGraw Laboratories Division, American Hospital Supply Corp, Evanston, Illinois, USA. Alternative agents include Plasmagel and Dextran. 
obtain average numbers of 3-4 $\times 10^{10}$ cells per procedure (Russell and Powles, 1976). Djerassi et al (1975) have in fact been able to report mean yields ranging from 3 to $10 \times 10^{10}$ cells in unstimulated donors.

\section{SIDE EFFECTS}

The most common complication experienced by donors is a sensation of light-headedness. Our experience is that this tends to be encountered somewhat more frequently with the Haemonetics separator perhaps because the changes in blood volume are greater with this machine. More severe vasovagal attacks may occur with any machine. Loss of consciousness in the supine position has been reported (Buchholz et al, 1975) and we have observed a similar episode. Shivering attacks may occur in a small percentage of donors (Buchholz et al, 1975) although we have not seen this complication in over a hundred donations using filtration leukapheresis. Repeated daily filtration leukapheresis of a single donor has been used without ill effect (Schiffer et al, 1975b). The use of ACD with the Haemonetics separator may produce nausea and paraesthesiae in some donors but on the whole the use of this machine appears to be well tolerated (Huestis et al, 1975; Szymanski et al, 1973). Complications of anticoagulation with heparin have not been reported and it does not seem to be necessary to reverse its effect with protamine. Likewise, we are not aware of any immediate hazards associated with the use of sedimenting agents or steroids in healthy donors.

While there is no evidence to date that these collection procedures present any short-term risks to donors, it is imperative that any procedure widely practised on normal individuals should be known to be as safe as possible. This fact has led some workers, ourselves included, to have some reservations concerning the use, in particular, of sedimenting agents. Anyone considering using these techniques should be aware of the ethical implications of infusing foreign substances into normal individuals where the longterm effects in particular are unpredictable

\section{DONOR SELECTION}

Careful selection of donors may prevent unnecessary discomfort for some and possible danger to the occasional individual. We feel it is preferable to err on the side of caution and generally to restrict the age of donors to between 18 and 50 years. It is probable that donors over 50 would have a greater risk of cardiac arrhythmia or cerebrovascular accident, however slight. A general rule of this kind, which can be relaxed on occasion, ensures that extra care is taken if selection of an older donor is unavoidable because no one else is available. No donor should have a history of a medical condition which would be a contraindication to anticoagulation or to routine blood donation. It is important to check that the veins are of adequate size in order to avoid subjecting the donor to a lengthy and perhaps fruitless procedure. It is useful to have a printed information sheet for donors to read and to require them to sign a consent form. Individuals who appear to be excessively anxious or who have a history of fainting should not be asked to undergo the procedure.

Donors should be ABO group compatible with the recipient and have a normal blood count. The use of close relatives makes a degree of histocompatibility more probable but is to be avoided if future bone marrow transplantation is contemplated (see below).

EFFECT ON DONOR BLOOD COUNTS

Both methods of leukapheresis produce changes, usually transient, in donor blood counts (Higby et al, 1975; Russell and Powles, 1976). A fall in haemoglobin level of about $10 \mathrm{~g} / \mathrm{l}$ usually occurs, largely due to haemodilution by saline. The granulocyte count may show a profound fall during the first $\mathbf{3 0}$ minutes of filtration leukapheresis (Schiffer et al, 1975a), but at the end of both procedures about $80 \%$ of donors will show an increased count, even without the use of steroids. The filtration method tends to remove more platelets than the centrifuge and may reduce the count to less than $50 \%$ of the initial level. Although the haemoglobin and platelets usually return to their initial levels very quickly (Higby et al, 1975), a more prolonged effect is occasionally seen (Russell and Powles, 1976).

\section{Use of Donors with Chronic Granulocytic Leukaemia}

Patients with CGL are a valuable source of granulocytes for transfusion (Morse et al, 1966; Mathé et $a l, 1971)$. With high blood counts it is possible to use whole fresh blood or to concentrate the granulocytes after sedimenting the red cells which can then be reinfused into the donor. If a centrifugal separator is used, numbers of granulocytes up to $10^{12}$ can be removed in exchange for whole blood or plasma, and this may have some therapeutic value for the donor. Where the count is lower, between about 20 and $100 \times 10^{9} / 1$, the centrifuge will provide useful yields which can be improved with the use of sedimenting agents. With these lower counts it is important that the donor should be fully aware that the procedure will be of little direct benefit to him.

CGL is not a common disease and it is often difficult to find a suitable donor. A register of such patients has been set up in the London area in an attempt to get over this problem, and this principle could be extended to other parts of the country. 


\section{Behaviour of Infused Granulocytes}

The behaviour of granulocytes transfused into allogeneic recipients is complex (Boggs, 1974), and care is needed in interpreting the results of any in vitro and in vivo studies. Examination of structure and function in vitro may be useful to assess damage to the cells by the collection procedures, but the ability of such tests to predict behaviour in vivo may be limited. Thus a cell may be structurally and functionally intact on in vitro testing but still unable to perform a useful function in vivo because of factors such as antibodies operating in the recipient. Some assessment of activity in vivo may be provided by isotopic labelling of cells and counting the radioactivity of an infected area, or by detecting migration to skin windows. However, even these tests can indicate activity in only a proportion of infused cells. The increment in granulocyte count, commonly measured one hour after infusion, is similarly difficult to interpret. Although there is no clear relationship between such increments and clinical response, the fact that small increments tend to be associated with factors which might be expected to give a poor response, such as antibodies, apparently damaged cells, and splenic sequestration (Eyre $e t$ al, 1970; Herzig et al, 1972), suggests that this measurement may have some value. On the other hand, a low increment may not necessarily mean that the transfusion is of little value in a given case as it may simply indicate a more profound deficit in total granulocyte pool or increased utilization due to infection (Morse et al, 1966; Boggs, 1974). Clearly, the only satisfactory answer concerning the value of granulocyte transfusion can be provided by clinical response. On an individual basis response can be assessed by lysis of fever, resolution of infected lesions or survival for a given length of time. However impressive anecdotal experience may be, the most satisfying evidence is that provided by controlled clinical trials. These have understandably been few in number and are liable to become more difficult to perform ethically as evidence for the value of this form of treatment accumulates.

With these qualifications in mind some of the evidence for the value of transfused normal and CGL cells will be briefly reviewed.

\section{NORMAL CELLS}

There is some evidence that the collection of granulocytes by filtration damages the cells to some extent. Herzig et al (1972) reported that light and electron microscopy revealed cytoplasmic vacuolation and a ragged appearance to the cell membrane in $15-20 \%$ of filtered cells. While such changes need not necessarily imply functional impairment (Schiffer et al, 1975b) the function of filtered cells as measured by phagocytic and bactericidal tests may be impaired to some extent (Herzig et al, 1972; Higby et al, 1975.) Such changes do seem to be at least partially reversible by restoring the cells to a more physiological medium (Debelak et al, 1974; Sanel et al, 1975). In vitro bactericidal and phagocytic tests appear to be performed normally by cells collected by the centrifuge (Mishler et al, 1974). In vivo, post transfusion increments corrected for dose are lower with filtered cells than with those collected by the centrifuge (Graw et al, 1972; Schiffer et al, 1975b), and experiments in dogs have shown that considerable numbers of filtered cells are rapidly removed by the spleen (Herzig et al, 1972).

It appears, therefore, that an equivalent dose of cells collected by the centrifuge is likely to be more effective. Nevertheless, there is good evidence that filtered granulocytes can perform some functions in vivo. Debelak et al (1974) rendered dogs neutropenic by irradiation and were able to protect them from septicaemic episodes by using filtered granulocytes. Skin window experiments in man have shown that filtered cells can migrate to sites of infection (Schiffer et al, 1975b), and appreciable numbers of these cells may occasionally be seen to circulate in the recipient for many hours (fig 2).

In 1972 Graw et al reported a controlled trial in which they concluded that normal cells collected by both methods were of value, particularly if four or more daily transfusions were given. Thus all 12 patients receiving four or more consecutive daily

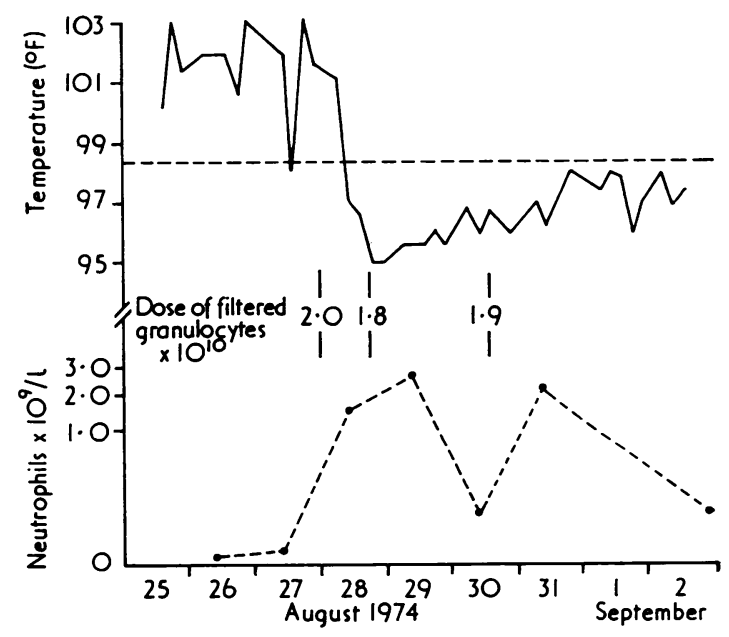

Fig 2 Case 1. Response of temperature and granulocyte count to three granulocyte transfusions. 
granulocyte transfusions had complete recovery compared with 5 of 19 patients in their appropriate control group (Graw et al, 1972). More recently, the clinical effectiveness of filtered granulocytes has been confirmed by Higby et al (1975). In their study only 5 of 19 control patients survived to day 20 , compared with 15 of 17 patients who received four consecutive daily transfusions.

The following case history describes a situation in which the transfusion of filtered granulocytes appears to have been useful.

\section{Case 1}

T. C., a 5-year-old girl, was admitted to hospital with epistaxis following chemotherapy for acute lymphoblastic leukaemia. On admission the haemoglobin level was $60 \mathrm{~g} / 1$, platelet count $5 \times 10^{9} / 1$, and white count $1.9 \times 10^{9} / 1$ with $1 \%$ neutrophils. She became febrile and treatment with ampicillin was begun. On the third day she was transferred to the Royal Marsden Hospital for supportive care. At this stage she had clinical and radiological evidence of a chest infection, and gentamicin and carbenicillin were added to the antibiotic regime. Figure 2 shows the subsequent course of her temperature and granulocyte counts. Her condition initially deteriorated so that 48 hours after transfer she was cyanosed, in an oxygen tent, and critically ill. After an infusion of $2 \times 10^{10}$ granulocytes collected by filtration leukapheresis from her father her temperature fell and her condition began to improve. The following morning, 16 hours after the transfusion, her granulocyte count was $1.33 \times 10^{9} / 1$. A second transfusion of $1.8 \times 10^{10}$ cells from an aunt was given 24 hours after the first, and the count the following morning had increased to $2 \cdot 27 \times 10^{9} / 1$. Although the temperature remained normal and her clinical condition improved she was given another transfusion of $1.9 \times 10^{10}$ cells from her father 48 hours after the second. The granulocyte count, which had fallen to $0.23 \times 10^{9} / 1$ before the transfusion, rose to $1.98 \times 10^{9} / 1$ at 16 hours and then fell again 24 hours later to $0.23 \times$ $10^{9} / 1$. The patient continued to improve and her granulocyte count showed spontaneous recovery, reaching $1.0 \times 10^{9} / 1$ eight days later. She was discharged from hospital four weeks after admission and remains well and in remission nine months later.

This case history illustrates a number of points. The improvement in the temperature and clinical condition seems to have been related to the granulocyte transfusion. Moreover, the increased granulocyte counts observed 16 hours after transfusion are unlikely to have been due to spontaneous recovery because the levels fell again after a further 24 hours in the absence of further transfusion and the eventual spontaneous recovery took over a week to produce comparable figures. The fact that the transfused cells could persist for so long in the circulation is encouraging and may be related both to the relatively high dose which could be given to a child and also to a degree of histocompatibility achieved by using relatives as donors (see below).

\section{Reactions in Recipients of Normal Cells}

Transfusion reactions to normal granulocytes seem to occur more often when filtered cells are used. This could possibly reflect the greater degree of cell damage in these preparations (Schiffer et al, 1975b). A small increase in temperature accompanied by shivering has been reported in up to $60 \%$ of recipients of these cells (Higby et al, 1975). More severe symptoms, which may include respiratory difficulty and hypotension, have occurred in a significant number of patients. Thus Schiffer et al (1975b) reported reactions classified as 'moderately severe' in more than $25 \%$ of their patients. There appears to be no clear relationship between such reactions and HLA incompatibility or detectable leucocyte antibodies (Schiffer et al, 1975b). These reactions may be controlled by stopping the transfusion and giving antipyretics, antihistamines, and corticosteroids. It may in fact be possible to avert them altogether by giving the cells slowly (about $1 \times 10^{10}$ per hour) and premedicating the recipient with hydrocortisone and antihistamines (Djerassi et al, 1975).

\section{CGL CELLS}

Although in vitro tests of the bactericidal and phagocytic properties of CGL cells sometimes show that they do not function quite as well as normal granulocytes (Penny and Galton, 1966), any defect there may be is probably compensated for by the large numbers of these cells which are available. In vivo studies have shown that such cells have the capacity to ingest organisms and to migrate to inflammatory lesions (Eyre et al, 1970; Shohet, 1968). Transfusion of large numbers of CGL cells can produce substantial increments in leucocyte counts in the recipient. For example, Morse et al (1966) found a median increase in circulating granulocyte count of $1 \times 10^{9} / 1$ one hour after transfusion. In addition, younger cells may mature in the recipient and occasionally a temporary haemopoietic graft is produced with prolongation of the therapeutic effect (Buckner et al, 1969; Mathé et al, 1971). Although their clinical studies were not controlled, many investigators have concluded that CGL cells are of considerable value in the control of infection (Eyre et al, 1970; Mathé et al, 1971; Lowenthal et al, 1975). Indeed, it is difficult to avoid the impression that a large number of CGL cells may 
succeed in some cases where normal cells are inadequate. This is illustrated in the following case history.

\section{Case 2}

A 7-year-old girl with aplastic anaemia developed a chest infection which was treated with gentamicin, cloxacillin, and carbenicillin starting on 18 April 1974. In addition she was given daily transfusions of granulocytes collected by filtration from unrelated donors (fig 3). After a week of treatment her condition had deteriorated and she was given an infusion of $2.1 \times 10^{10}$ irradiated CGL cells without effect. She was then critically ill and on 20 April was given $1.2 \times 10^{10}$ non-irradiated cells from the same donor. Her condition improved dramatically and a second dose of $2.1 \times 10^{10}$ non-irradiated cells was given three days later. Bone marrow specimens on 1 and 3 May were consistent with CGL, and dividing cells were shown to contain the Philadelphia chromosome. Two further transfusions of irradiated cells were given on 2 and 6 May. The peripheral granulocyte count, which included many immature forms and had risen to over $2 \times 10^{9} / 1$ by 30 April, remained between 1 and $4 \times 10^{9} / 1$ for the following eight days. On 10 May she began treatment with cyclophosphamide, $1.25 \mathrm{~g}$ daily for four days, and a bone marrow transplant from her sister was performed on 15 May. Subsequent blood counts were complicated by the fact that she then received daily transfusions of irradiated cells from a patient with a myeloproliferative syndrome, but by 28 May the marrow showed a virtual absence of haemopoietic cells. The attempted graft failed to take, and a second attempt a month later was also a failure.

The first lesson to be learnt from this case concerns the failure of daily transfusions of filtered granulocytes to control the infection. Although the yields from several donors were somewhat unsatisfactory, daily transfusions of 0.34 to $3.5 \times 10^{10}$ cells might have been expected to produce some improvement in a child of this age. Failure can possibly be attributed to a combination of severe infection, HLA incompatibility, and profound neutropenia. Even a dose of $2.1 \times 10^{10}$ irradiated CGL cells produced no response, and it was only after a somewhat lower dose of non-irradiated cells were given that dramatic improvement was seen. Further irradiated cells were not given until the patient was very much better. Evidence for a haemopoietic graft was provided by the well-maintained neutrophil and platelet counts and the presence of dividing $\mathrm{Ph}^{1}$ positive cells in the bone marrow. The rationale for irradiating granulocyte transfusions, and withholding the irradiation on occasion, is discussed below.

\section{Complications of Transfusion of CGL Cells}

Transfusion reactions may occur as with normal granulocytes and they tend to be more severe, possibly due to the larger numbers usually given. An association of such reactions with the presence of leucocyte antibodies has been reported (Goldstein $\boldsymbol{e t}$ al, 1971). Particularly alarming reactions, characterized by respiratory distress and cyanosis, may occur and have been attributed to the sequestration

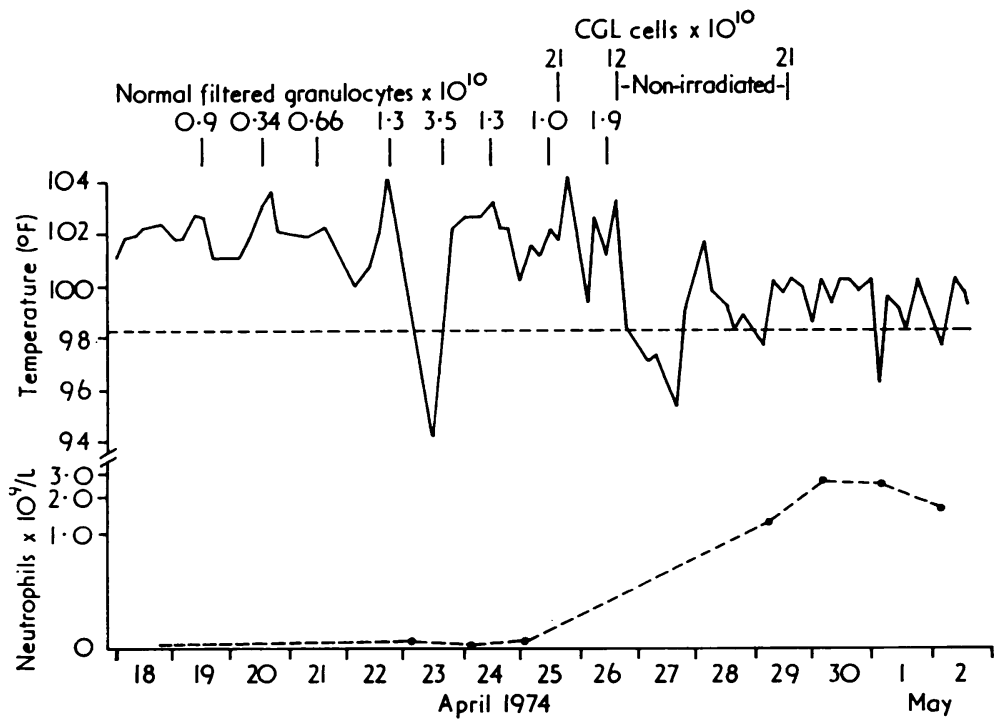

Fig 3 Case 2. Temperature and neutrophil counts. All transfusions were irradiated with $1500 \mathrm{r}$ except where indicated. 
of large numbers of cells in the pulmonary capillary bed (Mathé et al, 1971).

The development of grafts of CGL persisting for several weeks has occasionally been reported (Lowenthal et al, 1975; Coltman et al, 1975). In addition, graft versus host (GVH) disease may occur in immunosuppressed patients (Graw et al, 1970; Mathé et al, 1971).

\section{Irradiation of Granulocytes}

The decision to irradiate a granulocyte suspension depends on the source of the cells and the clinical state of the recipient. Cells from normal donors are irradiated in order to prevent division of lymphoid cells and the development of GVH disease in immunosuppressed individuals. A dose of $1500 \mathrm{rad}$ is commonly used. This figure is based on the dose required to abolish the response of lymphocytes in mixed lymphocyte culture and apparently does not alter normal granulocyte function (Graw $e$ t al, 1970). We are not aware of any reports of GVH disease following irradiation of granulocyte suspensions with this dose. As the development of GVH disease probably depends on the dose of lymphocytes infused it must be remembered that cells collected by the centrifuge contain a relatively high number of lymphocytes whereas filtered preparations usually contain less than $5 \%$. However, we feel it is safest routinely to irradiate all blood products where there is severe immune depression.

In the case of CGL cells irradiation will inhibit not only division of lymphoid cells but also that of stem cells which might otherwise be responsible for producing a haemopoietic graft. There is some evidence that irradiation of CGL cells may impair their effectiveness (Bussel et al, 1975), and the establishment of a temporary graft may be beneficial, as in our case 2 above. In addition, such a graft may exert a temporary antileukaemic effect which is related to GVH disease (Mathé et al, 1971). These potential benefits must be weighed against the risk of obtaining a persistent graft with or without a potentially fatal GVH reaction. We feel that there should be no hesitation in using non-irradiated CGL cells in situations where there has been no response to irradiated cells and it is felt that the infection will otherwise prove fatal.

\section{Donor Recipient Matching}

Persistence of transfused granulocytes in the circulation has been shown to decrease with increasing ABO and HLA incompatibility between donor and recipient and the presence of leucocyte antibodies in the recipient (Goldstein et al, 1971; Graw et al, 1972).
This raises the possibility that these factors may also impair clinical effectiveness but at present there is no direct evidence that this is the case. Unfortunately time does not always permit in vitro tests other than ABO grouping but the use of relatives as donors often leads to some degree of histocompatibility. However, the use of related donors should be avoided in situations where bone marrow transplantation is contemplated because the graft is less likely to take if blood products from relatives have previously been given (Thomas et al, 1975).

\section{Indications for Granulocyte Transfusion}

While any infection in which neutropenia is a significant factor might be expected to benefit from granulocyte transfusion, the limited facilities usually available means that in practice only a small minority of patients are able to receive such support. The decision to provide support depends on a balanced assessment of the clinical situation with particular reference to the nature of the underlying disease and the estimated chance of controlling the infection with antibiotics alone. In a situation where most patients treated in this way are suffering from a malignant disease it may be justifiable to restrict the provision of granulocyte transfusion to those patients in whom it is felt that a remission of the disease can be achieved. It does in fact appear to be more difficult to control infection in cases where the underlying disease is not responding to chemotherapy (Smith $e t$ $a l, 1975)$. Because many infections appear to be controllable by antibiotic therapy alone, even in the presence of severe neutropenia, it seems reasonable to try the effect of antibiotics alone for $\mathbf{4 8}$ hours from the onset of the infection. If the infection is already advanced when first seen, granulocyte support should be considered from the outset if the cells are readily available. Although infection in the presence of a neutrophil count of less than $0.5 \times 10^{9} / 1$ is often taken as an indication for granulocyte transfusion (Graw et al, 1972; Higby et al, 1975) our own experience is that such transfusions are rarely requested until the count has fallen below $0.2 \times$ $10^{9} / 1$. This would in fact appear to agree with the experience of Higby et al (1975). Although they stated that a count of less than $0.5 \times 10^{9} / 1$ qualified an infected patient for entry into their trial, their data reveal that all 36 of their patients had granulocyte counts of $0.2 \times 10^{9} / 1$ or less at the beginning of the study.

HOW MANY CELLS SHOULD BE GIVEN?

Several investigators have reported a clear relationship between response to transfusion and both the numbers of cells infused and the number of trans- 
fusions given (Morse et al, 1966; Graw et al, 1972; Lowenthal et al, 1975). In their controlled trial, Graw et al found that the difference in outcome of infection between their control and treated groups reached statistical significance only when four consecutive daily transfusions were given. It seems that the decision to give granulocytes should involve being prepared to give daily transfusions for at least four days. Clearly, the more cells given per transfusion the more useful are they likely to be. The daily doses of cells given by most groups of workers generally reflect the number of cells which can reasonably be removed from one donor in a single procedure. Analysis of the cell numbers given by investigators who have claimed some benefit from granulocyte transfusion suggests that one should aim for a minimum of $2 \times 10^{10}$ normal cells per day, a figure which can usually be achieved using filtration leukapheresis or a continuous-flow cell separator with steroids and a sedimenting agent (Russell and Powles, 1976).

\section{Choice of Collection Procedure}

Any decision to provide a granulocyte transfusion service must depend not only on the likely demand but also on the finances available and the other purposes for which the equipment would be used. Economic arguments for such a service can be reinforced by considering the potential saving of money spent, for example, on antibiotics and additional hospitalization.

The table is intended to be a very rough guide to the relative merits of the various available techniques. If granulocyte transfusion is to be the only function performed by the equipment then economically it is impossible to consider any method other than filtration even if the cells so obtained are damaged to some extent. This is because adequate yields are obtainable using a machine which can be constructed by any competent workshop bringing this method within the reach of any large general hospital. Alternatively, a relatively cheap portable device comprising a rotary pump linked to a bubble detector and warning system is commercially available ${ }^{1}$. A unit such as ours, which already possesses centrifugal cell separators, may still prefer to use filters because of their convenience and because of reservations concerning the use of sedimenting agents in normal donors, although there is no evidence at present that these are harmful.

The cost of buying and operating a cell centrifuge is high so these machines should be bought only if they will be used for other functions in addition to

${ }^{1}$ Fenwal Ltd, Travenol Laboratories, Thetford, Norfolk IP24 3SE. granulocyte collection. The Haemonetics Separator was originally designed for platelet collection, a function it performs extremely well (Tullis et al, 1971 ; Szymanski et al, 1973). It is a valuable instrument to have if provision of a platelet support service is the primary consideration. If sedimenting agents are used, this centrifuge can provide yields of granulocytes which are at least adequate for children (Scarffe, 1975). The pumps on this machine can also be used for the filtration method. The continuousflow cell separators, although somewhat more versatile, are considerably more expensive and should only be purchased if required to perform other functions, such as removal of acute leukaemia cells for immunotherapy and plasma exchange in patients with paraproteinaemias (Powles et al, 1971; Powles et al, 1974).

\section{Conclusion}

We feel that there is now enough evidence to suggest that granulocyte transfusion is a valuable procedure in certain clinical situations. However, there is still a need for controlled trials to define more precisely those situations in which this form of treatment can be used to the greatest advantage. For example, it would be useful to know if prophylactic granulocyte transfusions are needed in addition to other preventive measures during marrow transplantation, or if early treatment of certain specific infections, such as perianal cellulitis, could make enough difference to consider using them as a routine in such conditions.

The aim of any unit involved in a cytotoxic chemotherapy programme for haematological malignancy should be to produce a situation in which very few patients with controllable malignant disease die of infection. The addition of granulocyte transfusions to a good programme of supportive care may help to achieve this aim.

We wish to thank the Leukaemia Research Fund of Great Britain for financing this work.

\section{References}

Athens, J. W., Haab, O. P., Raab, S. O., Mauer, A. M., Ashenbrucker, H., Cartwright, G. E., and Wintrobe, M. M. (1961). Leukokinetic studies. IV: The total blood, circulating and marginal granulocyte pools and the granulocyte turnover rate in normal subjects. $J$. clin. Invest., 40, 989-995.

Benbunan, M., Bussel, A., Grange, M. J., Reviron, J., and Bernard, J. (1975). Collection by blood cell separator and in vitro function of normal granulocytes. In Leucocytes: Separation, Collection and Transfusion, edited by J. M. Goldman and R. M. Lowenthal, pp. 81-87. Academic Press, New York.

Boggs, D. R. (1974). Transfusion of neutrophils as prevention or treatment of infection in patients with neutropenia. New Engl.J. Med., 290, 1055-1062. 
Buchholz, D. H., Schiffer, C. A., Wiernik, P. H., Betts, S. W., and Reilly, J. A. (1975). Granulocyte transfusion: donor response to repeated leukapheresis: In Leucocytes: Separation, Collection and Transfusion, edited by J. M. Goldman and R, M, Lowenthal, pp. 177-189. Academic Press, New York.

Buckner, D., Graw, R. G., Jr., Eisel, R. J., Henderson, E. S., and Perry, S. (1969). Leukapheresis by continuous-flow centrifugation (CFC) in patients with chronic myelocytic leukaemia (CML). Blood, 33, 353-369.

Bussel, A., Benbunan, M., Grange, M. J., Boiron, M., and Bernard, J. (1975). Comparison of clinical results induced by irradiated and non-irradiated CML cell transfusions and the relationship to in vitro studies. In Leucocytes: Separation, Collection and Transfusion, edited by J. M. Goldman and R. M. Lowenthal, pp. 395-401. Academic Press, New York.

Coltman, C. A., Jr., Uhl, G. S., Bearden, J. D., and Ratkin, G. A. (1975). Marrow engraftment with extreme leucocytosis in a patient with non-Hodgkin's lymphoma. In Leucocytes: Separation, Collection and Transfusion, edited by J. M. Goldman and R. M. Lowenthal, pp. 385-393. Academic Press, New York.

Debelak, K. M., Epstein, R. B., and Andersen, B. R. (1974). Granulocyte transfusions in leukopenic dogs: in vivo and in vitro function of granulocytes obtained by continuous-flow filtration leukopheresis. Blood, 43, 757-766.

Djerassi, I., Kim, J. S., Mitrakul, C., Suvansri, U., and Ciesielka, W. (1970). Filtration leukopheresis for separation and concentration of transfusable amounts of normal human granulocytes. J. Med. (Basel), 1, 358-364.

Djerassi, I., Kim, J. S., Suvansri, U., Ciesielka, W., and Lohrke, J. (1975). Filtration leukopheresis: principles and techniques for harvesting and transfusion of filtered granulocytes and monocytes. In Leucocytes: Separation, Collection and Transfusion, edited by J. M. Goldman and R. M. Lowenthal, pp. 123-136. Academic Press, New York.

Eyre, H. J., Goldstein, I. M., Perry, S., and Graw, R. G., Jr. (1970). Leukocyte transfusions: function of transfused granulocytes from donors with chronic myelocytic leukaemia. Blood, 36, 432-442.

Goldstein, I. M., Eyre, H. J., Terasaki, P. I., Henderson, E. S., and Graw, R. G., Jr. (1971). Leukocyte transfusions: role of leukocyte alloantibodies in determining transfusion response. Transfusion, 11, 19-24.

Graw, R. G., Jr., Buckner, C. D., Whang-Peng, J., Leventhal, B. G., Krüger, G., Berard, C., and Henderson, E. S. (1970). Complication of bone-marrow transplantation. Graftversus-host disease resulting from chronic-myelogenousleukaemia leucocyte transfusions. Lancet, 2, 338-341.

Graw, R. G., Jr., Herzig, G., Perry, S., and Henderson, E. S. (1972). Normal granulocyte transfusion therapy: treatment of septicemia due to gram-negative bacteria. New Engl.J. Med., 287, 367-371.

Greene, W. H., Moody, M., Schimpff, S., Young, V. M., and Wiernik, P. H. (1973). Pseudomonas aeruginosa resistant to carbenicillin and gentamicin: epidemiologic and clinical aspects in a cancer center. Ann. intern. Med., 79, 684-689.

Herzig, G. P., Root, R. K., and Graw, R. G., Jr. (1972). Granulocyte collection by continuous-flow filtration leukapheresis. Blood, 39, 554-567.

Higby, D. J., Yates, J. W., Henderson, E. S., and Holland, J. F. (1975). Filtration leukapheresis for granulocyte transfusion therapy. New Engl.J. Med., 292, 761-766.

Huestis, D. W., Goodsite, L. M., Price, M. E., and White, R. F. (1975). Granulocyte collection with the Haemonetics blood cell separator. In Leucocytes: Separation, Collection and Transfusion, edited by J. M. Goldman and R. M. Lowenthal, pp. 208-219. Academic Press, New York.
Jameson, B., Lynch, J., Gamble, D. R., and Kay, H. E. M. (1971). Five-year analysis of protective isolation. Lancet, 1 , 1034-1040.

Levine, A. S., Graw, R. G. Jr., and Young, R. C. (1972). Management of infections in patients with leukemia and lymphoma: current concepts and experimental approaches. Semin. Hemat., 9, 141-179.

Levine, A. S., Siegel, S. E., Schreiber, A. D., Hauser, J., Preisler, H., Goldstein, I. M., Seidler, F., Simon, R., Perry, S., Bennett, J. E., and Henderson, E. S. (1973). Protected environments and prophylactic antibiotics. A prospective controlled study of their utility in the therapy of acute leukemia. New Engl. J. Med., 288, 477-483.

Lowenthal, R. M., Goldman, J. M., Buskard, N. A., Murphy, B. C., Grossman, L., Storring, R. A., Park, D. S., Spiers, A. S. D., and Galton, D. A. G. (1975). Granulocyte transfusions in treatment of infections in patients with acute leukaemia and aplastic anaemia. Lancet, 1, 353-358.

McCredie, K. B., Hester, J. P., Vallejos, C., and Freireich, E. J. (1975). Clinical results of granulocyte transfusions using normal donors. In Leucocytes: Separation, Collection and Transfusion, edited by J. M. Goldman and R. M. Lowenthal, pp. 287-291. Academic Press, New York.

Mathé, G., Amiel, J. L., and Schwarzenberg, L. (1971). Bone Marrow Transplantation and Leucocyte Transfusions, Thomas, Springfield, Illinois.

Mishler, J. M., Hadlock, D. C., Fortuny, I. E., Nicora, R. W., and McCullough, J. J. (1974). Increased efficiency of leukocyte collection by the addition of hydroxyethyl starch to the continuous-flow centrifuge. Blood, 44, 571-581.

Morse, E. E., Freireich, E. J., Carbone, P. P., Bronson, W., and Frei, E., III (1966). The transfusion of leukocytes from donors with chronic myelocytic leukaemia to patients with leukopenia. Transfusion, 6, 183-192.

Penny, R. and Galton, D. A. G. (1966). Studies on neutrophil function, II: Pathological aspects. Brit. J. Haemat., 12, 633-645.

Powles, R. L., Lister, T. A., Oliver, R. T. D., Russell, J., Smith, C., Kay, H. E. M., McElwain, T. J., and Hamilton Fairley, G. (1974). Safe method of collecting leukaemia cells from patients with acute leukaemia for use as immunotherapy. Brit. med.J., 4, 375-379.

Powles, R. L., Smith, C., Kohn, J., and Hamilton Fairley, G. (1971). Method of removing abnormal protein rapidly from patients with malignant paraproteinaemias. Brit. med. J., 3, 664-667.

Russell, J. A. and Powles, R. L. (1976). In Clinics in Haematology, Vol. 5, Blood transfusion and blood products, edited by J. D. Cash, pp. 81-93. W. B. Saunders.

Sanel, F. T., Aisner, J., Tillman, C. J., Schiffer, C. A., and Wiernik, P. H. (1975). Evaluation of granulocytes harvested by filtration leukapheresis: Functional, histochemical and ultrastructural studies. In Leucocytes: Separation, Collection and Transfusion, edited by J. M. Goldman and R M. Lowenthal, pp. 236-248. Academic Press, New York.

Scarffe, J. H. (1975). Paper presented at International Society of Haematology Meeting, London, August 1975.

Schiffer, C. A., Aisner, J., and Wiernik, P. H. (1975a). Transient neutropenia induced by transfusion of blood exposed to nylon fiber filters. Blood, 45, 141-146.

Schiffer, C. A., Buchholz, D. H., Aisner, J., Betts, S. W., and Wiernik, P. H. (1975b). Clinical experience with transfusion of granulocytes obtained by continuous-flow filtration leukopheresis. Amer.J. Med., 58, 373-381.

Schimpff, S. C., Greene, W. H., Young, V. M., Fortner, C. L., Jepsen, L., Cusack, N., Block, J. B., and Wiernik, P. H. (1975). Infection prevention in acute nonlymphocytic leukaemia: Laminar air flow room reverse isolation with oral, nonabsorbable antibiotic prophylaxis. Ann. intern. Med., 82, 351-358. 
Shohet, S. B. (1968). Morphologic evidence for the in vivo activity of transfused chronic myelogenous leukaemia cells in a case of massive staphylococcal septicemia. Blood, 32, 111-118.

Smith, I. E., Powles, R. L., Clink, H. MacD., Jameson, B., Kay, H. E. M., and McElwain, T. J. (1975). Early deaths in acute myelogenous leukaemia. Cancer (In press).

Sussman, L. N. and Colli, W. (1975). Harvesting of granulocytes using a hydroxyethyl starch solution. In Leucocytes: Separation, Collection and Transfusion, edited by J. M. Goldman and R. M. Lowenthal, pp. 220-226. Academic Press, New York.

Szymanski, I. O., Patti, K., and Kliman, A. (1973). Efficacy of the Latham blood processor to perform plateletpheresis. Transfusion, 13, 405-411.

Thomas, E. D., Storb, R., Clift, R. A., Fefer, A., Johnson, F. L., Neiman, P. E., Lerner, K. G., Glucksberg, H., and Buckner, C. D. (1975). Bone marrow transplantation. New Engl. J. Med., 292, 832-843, 895-902.

Tullis, J. L., Tinch, R. J., Baudanza, P., Gibson, J. G., DiForte, S., Conneely, G., and Murthy, K. (1971). Plateletpheresis in a disposable system. Transfusion, 11, 368-377.

Yates, J. W. and Holland, J. F. (1973). A controlled study of isolation and endogenous microbial suppression in acute myelocytic leukemia patients. Cancer (Philad.), 32, 14901498. 